\title{
CERDOS, CAPRINOS Y NÁYADES. APROXIMACIÓN A LA EXPLOTACIÓN GANADERA Y FLUVIAL EN EL GUADALQUIVIR ENTRE EL NEOLÍTICO Y LA EDAD DEL COBRE (3500-2200 A.N.E.) \\ PIGS, CAPRINES AND FRESHWATER MUSSELS. APPROACH TO STOCKBREEDING AND FLUVIAL SHELLFISH GATHERING IN THE GUADALQUIVIR BASIN FROM NEOLITHIC TO COPPER AGE (3500-2200 BC)
}

\author{
RAFAEL M. MARTÍNEZ SÁNCHEZ*
}

\begin{abstract}
Resumen: En este trabajo se expone el estudio de los restos óseos animales recuperados en diversos contextos arqueológicos procedentes de los yacimientos de la Verduga Alta (Palma del Río, Córdoba) e Iglesia Antigua de Alcolea (Córdoba), datados hacia la segunda mitad del IV milenio a.n.e. Junto a ello, la revisión de datos disponibles referentes a los entornos de vega y campiña en la mayor parte de la Depresión del Guadalquivir ha servido para trazar un panorama de explotación y consumo animal basado sobre todo en la fauna doméstica, con ciertas diferencias entre las tierras bajas de la vega del Guadalquivir y las tierras altas de campiña y piedemonte subbético. Palabras Clave: Fauna, marisqueo, ganadería, Neolítico, Edad del Cobre, valle del Guadalquivir.
\end{abstract}

\section{INTRODUCCIÓN}

El estudio de las estrategias económicas desarrolladas durante la Prehistoria Reciente en el conjunto de la Depresión del Guadalquivir a través del análisis de los restos óseos animales, representa una necesaria vía de aproximación histórica que cuenta sin embargo con variados problemas de partida. Por un lado resulta

* Área de Prehistoria. Facultad de Filosofía y Letras. Universidad de Córdoba, Plaza Cardenal Salazar 3. 14071-Córdoba. Correo-e: martsancho@hotmail.com

\begin{abstract}
In this work we show the study of animal bones coming from some archaeological contexts located in La Verduga Alta (Palma del Río, Cordova) and Iglesia Antigua de Alcolea (Cordova), both sites dating after middle of IV millennium BC. In addition, we have revisited the available data related to the lowlands of Guadalquivir Valley, aiming to draw an overview of animal consumption and exploitation. Regarding to domesticated mammals and fluvial resources, some differences had been observed between the Guadalquivir floodplain lowlands and the southern higher lands (Campiña and Subbetic foothills).
\end{abstract}

Key words: Faunal remains, shellfish gathering, husbandry, Neolithic, Copper Age, Guadalquivir basin.

creciente el número de enclaves arqueológicos, en su mayoría poblados o áreas de hábitat al aire libre, detectados y parcialmente excavados a lo largo de la última década como resultado de una expansión urbanística y de infraestructuras sin precedentes históricos. Pese a ello, la actividad desarrollada por la llamada Arqueología de Urgencia no ha crecido desgraciadamente en paralelo a la publicación de los resultados, que derivados a menudo inevitablemente de la propia memoria preliminar, con demasiada frecuencia evidencian una frecuente ausencia de analíticas o aspectos particulares, viéndose especialmente perjudicados los estudios 
arqueozoológicos. A pesar de esta limitación, partiendo de los datos disponibles y aplicando una aproximación ecológica, consideramos que puede modelizarse la explotación ganadera extendida en la Depresión del Guadalquivir entre el final del Neolítico y la Edad del Cobre (3500-2200 a.n.e.), valiéndonos del estudio desarrollado aquí sobre los conjuntos excavados en dos enclaves arqueológicos de la vega del Guadalquivir Medio y de los datos obtenidos en investigaciones precedentes, haciendo énfasis en esta ocasión en un más que presumible aprovechamiento de los recursos fluviales.

Para trazar esta aproximación, debemos afrontar problemas de orden diverso. A la notoria escasez de estudios concretos publicados sobre la fauna mastozoológica de ciertos yacimientos del Sur de Iberia, minoría incluso en aquellos excavados, se suma la debilidad de los conjuntos analizados, los cuales habitualmente no llegan al centenar de restos. Por otra parte la heterogeneidad de las técnicas de cuantificación y estudio, la diversidad de los conjuntos analizados (resultado de la excavación de cuevas o poblados al aire libre), así como las dificultades cronológicas que presentan gran parte de los mismos, agrupados con frecuencia de forma inevitable en fases genéricas de gran extensión temporal, complican un panorama en el que los estudios faunísticos de síntesis, salvo excepciones (Harrison y Moreno 1985, Morales y Riquelme 2004), son sin duda escasos. El sesgo territorial resulta también importante en los estudios publicados, quedando la Depresión del Guadalquivir muy desdibujada y prácticamente desconocida tanto la vega estricta como el piedemonte de Sierra Morena en su sector central. Por ello, pese a la exigüidad del registro utilizado en este trabajo, creemos que éste puede llegar a representar un inicio para propuestas interpretativas de base más sólida y centradas en la explotación de los recursos animales en la Depresión del Guadalquivir entre el IV y el III milenio a.n.e.

\section{METODOLOGÍA}

Este trabajo integra los resultados del análisis de los restos óseos animales de la llamada Fase I de La Verduga Alta, correspondiente a los fondos 9, 15, 21, 22A y 104, así como del enclave de Iglesia Antigua de Alcolea, cuyo registro comprende los restos recuperados en las estructuras I, IV, VIII, XI y XII (tab. 1-4). Ambos conjuntos, ya de por sí heterogéneos, proceden de sedimentos que colmataban el interior de diversas estructuras circulares, algunas de ellas siliformes, pudiendo corresponder a depósitos diferenciales de carácter eventual o estratificados de forma episódica, en gran medida pertenecientes a restos alimentarios, sin poder excluir la posible presencia de deposiciones de origen multicausal o no relacionadas con el consumo humano. La datación de ambos conjuntos se sitúa en torno a la segunda mitad del IV milenio a.n.e., con una ergología característica de recipientes de paredes rectas y formas de carena baja.

El conjunto osteológico procedente de la excavación de las 11 estructuras repartidas entre la Fase I de La Verduga Alta e Iglesia Antigua de Alcolea (a partir de ahora VA-I e IAA), no resulta proporcionalmente abundante, por lo que las conclusiones potenciales deben tomarse con la necesaria cautela. El estado de conservación de los elementos anatómicos recuperados en ambos enclaves no es excesivamente deficiente, si bien muestra un alto índice de fracturación, lo cual sumado a la acción química desempeñada por agentes del suelo y factores biológicos que han causado lixiviación y erosiones radiculares, ha dificultado notablemente el trabajo de identificación y medición. Por razones de espacio y para evitar resultar prolijos, nos remitimos a la metodología, datos osteométricos, coeficientes usados, bibliografía complementaria y a la colección comparativa propia utilizada en trabajos anteriores (Martínez 2010). En cuanto a cohortes de edad, nos hemos basado en los criterios expuestos por el laboratorio de zooarqueología de la UAM, donde infantiles y juveniles se han agrupado en ciertos casos como inmaduros (Morales et al. 1994: 38).

A fin de poder integrar los resultados del análisis de estos dos enclaves ribereños en el conjunto general de la Depresión del Guadalquivir, hemos utilizado los registros arqueozoológicos publicados existentes en la región, los cuales se disponen desde el entorno de la paleodesembocadura del Gran Río al Alto Guadalquivir Jiennense, incluyendo algunos enclaves situados en el entorno subbético (fig. 1). Estos datos, aun procediendo de trabajos de muy diversa índole y extraídos a partir de metodologías muy diversas, nos han servido para tratar de alcanzar nuestro objetivo de visualizar una plausible explotación diferencial de las cabañas animales en función de pisos ecológicos diversos, incluyendo en este caso las posibilidades que la recolección de moluscos en medio acuático pudo ofrecer en entornos estrictamente fluviales y ambiente fluviomarino. En este último caso se pondrán de manifiesto las analogías presentes entre la recolección de moluscos bivalvos en el estuario del Guadalquivir y la Ría de Huelva, con la existente a lo largo del cauce del Guadalquivir a través del aprovechamiento de distintas especies de náyades de agua dulce. 

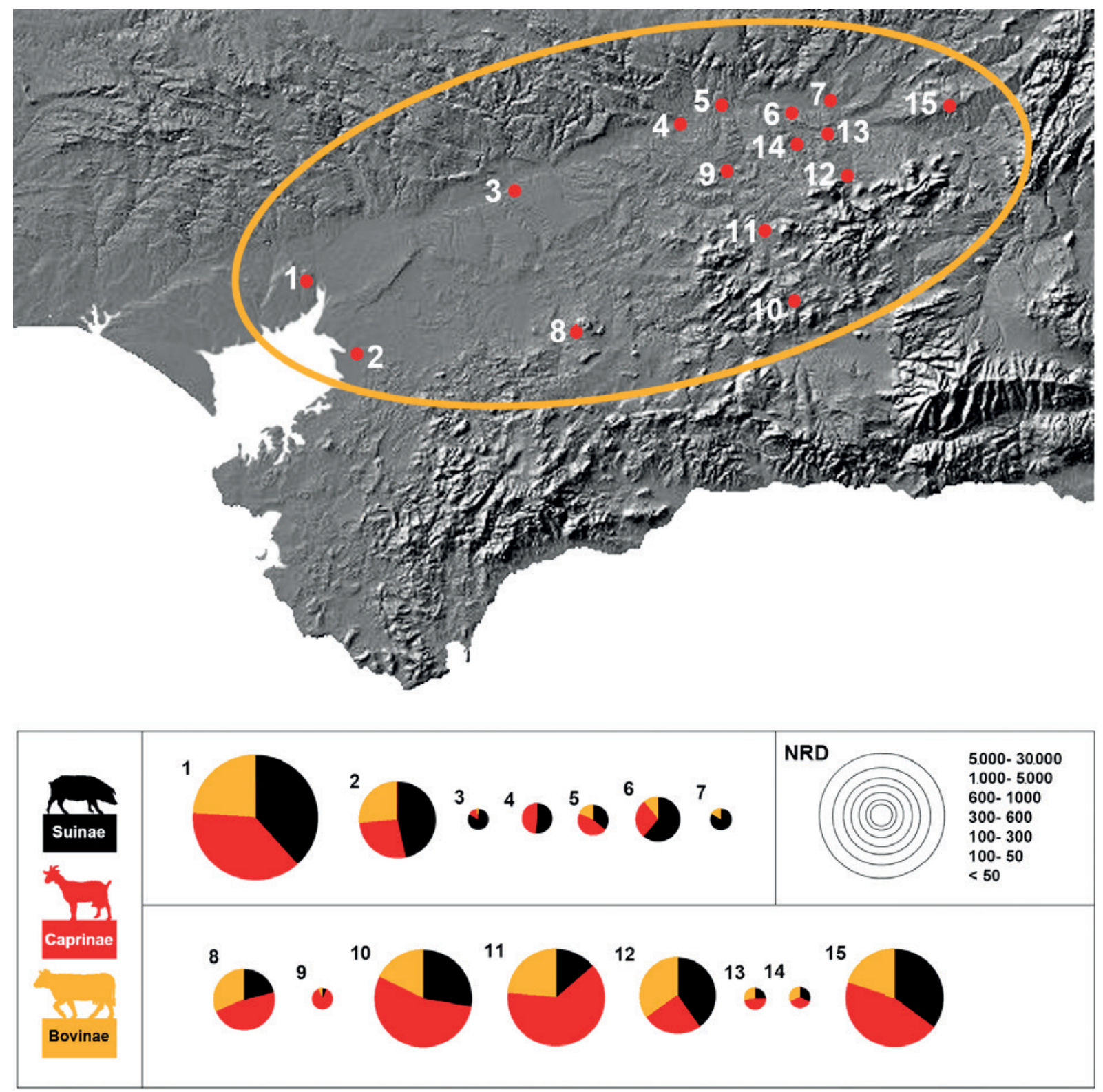

Figura 1. Emplazamiento de los conjuntos analizados en el texto y proporción que guarda en cada uno de ellos el trinomio caprino-suido-bovino por subfamilia (taxones salvajes incluidos): 1. Valencina de la Concepción (III milenio) (Hain 1982, Abril et al. 2010), 2. El Amarguillo II (III milenio a.n.e.) (Bernáldez 2009), 3. Verduga Alta Fase I (VA-I) (segunda mitad del IV milenio a.n.e.) (Martínez 2011), 4. Iglesia Antigua de Alcolea (segunda mitad del IV milenio a.n.e.) (Martínez 2011), 5. Llanete de los Moros (IV y III milenio a.n.e.) (Liesau 2000), 6. Los Pozos (segunda mitad del IV milenio a.n.e.) (Nocete 1994), 7. Sevilleja I (segunda mitad del IV milenio a.n.e.) (Cámara et al. 2008), 8. Gilena (tránsito del IV al III milenio a.n.e.) (Bernáldez 2009), 9. Torreparedones I (segunda mitad del IV milenio a.n.e.) (Hamilton 1999), 10. Castillejos de Montefrío (Fase Neolítico Final, segunda mitad del IV milenio a.n.e.) (Morales y Riquelme 2004), 11. Polideportivo de Martos I-III (segunda mitad del IV milenio a.n.e.) (Lizcano et al. 1992; Cámara et al. 2008), 12. Ciudad de la Justicia (Marroquíes Bajos) (III milenio a.n.e.) (Riquelme 2010), 13. Cazalilla (I-II) (III milenio a.n.e) (Nocete 1994), 14. Cortijo de la Torre (III milenio a.n.e.) (Nocete 1994), 15. Eras del Alcázar (Úbeda) (segunda mitad del III milenio a.n.e.) (Lizcano et al. 2009). El tamaño de los círculos guarda relación con el NRD total de mamíferos por cada yacimiento. 


\section{EL REGISTRO ARQUEOFAUNÍSTICO DE LA VERDUGA ALTA/FASE I E IGLESIA ANTIGUA DE ALCOLEA}

El yacimiento arqueológico de la Verduga Alta se encuentra a unos $4 \mathrm{~km}$ al suroeste del casco urbano del Palma del Río (Murillo 1988: 6), por lo que domina la confluencia del río Genil con el Guadalquivir, aproximadamente desde una cota de $130 \mathrm{~m}$ s.n.m. Este asentamiento fue excavado de forma continuada entre 2004 y 2005 previamente a la construcción de una gran balsa de riego. Los trabajos, dirigidos por Reyes Lopera y Rafael Nieto, permanecen inéditos en su totalidad, conservándose los materiales arqueológicos en los almacenes del Museo Arqueológico Municipal de Palma del Río, en donde tuvimos la oportunidad de estudiar una parte (Martínez et al. 2010b: 238; Martínez 2011). En total, todo el conjunto arqueozoológico contabilizado en la denominada Fase I se compone de 193 restos, de los cuales tan sólo 40 han resultado identificables por especie, género o subfamilia, para el caso de los mamíferos, y a nivel de familia, para el caso de anfibios y reptiles. El resto de los fragmentos (153), no han podido identificarse taxonómicamente debido principalmente a su alto grado de fragmentación. Entre éstos, siete fragmentos de concha pertenecen a valvas de náyades (Unionoida). Las alteraciones térmicas sobre el registro no resultan abundantes, estando presentes sobre el $12,8 \%$ de los fragmentos, el $6,8 \%$ del peso de los restos (PR) total. No disponemos de más precisiones sobre el contexto espacial relativo a los restos óseos correspondientes a cada fondo, al igual que otros detalles concretos de excavación arqueológica, relacionándose en la mayoría de los casos con elementos interpretables como desechos de carácter alimentario.

Por su parte, el enclave de Iglesia Antigua de Alcolea (IAA), se localiza en la orilla septentrional del río Guadalquivir y a unos $10 \mathrm{~km}$ río arriba del casco histórico de Córdoba. En la actualidad se ubica bajo el núcleo poblacional de la pedanía de Alcolea, a unos 115 m s.n.m. (Martínez et al. 2010a: 89). El conjunto recuperado en este emplazamiento asciende a 746 restos óseos (736 sin incluir las piezas dentales sueltas), de los cuales 708 corresponden a macrofauna (incluyendo lepóridos, como conejo y liebre), y 38 restos a microvertebrados, entre los que se han incluido micromamíferos, aves, lacértidos, peces y hasta fragmentos de cáscaras de huevo. Estos elementos de carácter microfaunístico se obtuvieron durante los trabajos de excavación realizados sobre la estructura XII, en la que se pudo flotar una considerable cantidad de sedimento.
Junto a éstos se han contabilizado por separado 55 fragmentos de valvas de náyades, repartidos en cuatro de las estructuras intervenidas.

$\mathrm{Al}$ corresponder en su mayor parte a esquirlas, el grado de identificabilidad de la macrofauna es muy reducido, apenas 99 restos clasificables por género o especie (incluyendo lepóridos sin determinar) frente a 609 restos no identificados, lo que supone apenas un $13 \%$ el total identificado. Por su parte aquellos restos no identificados corresponden en gran número a mesomamíferos indeterminados (320 restos), en su mayoría pertenecientes a medianos artiodáctilos, y 276 restos de mamíferos sin identificar. Dentro del conjunto identificado apenas diez y cinco restos se han incluido en el grupo de los macromamíferos y mesomacromamíferos, lo cual podría redundar en la débil presencia de grandes artiodáctilos o perisodáctilos en las bases económicas de los habitantes de este lugar (IAA).

Los restos en general cuentan con una frágil conservación, estando afectados por procesos intensos de carbonatación en algunos casos, muy sujetos a fragmentación antigua y diagenética, así como a erosiones radiculares. La mayoría de ellos se reduce a meras esquirlas, circunstancia que ha dificultado notablemente la identificación de la macrofauna bajo el rango de especie o género. Los elementos termoalterados suponen un $67,5 \%$ del total relativo al número de restos (NR), representando hasta un $53,2 \%$ para el caso del PR. Este hecho es correlacionable con el procesado de la fauna destinada a consumo humano, contando algunos restos con evidencias antrópicas de desarticulación o despiece que describiremos más adelante. Seguidamente expondremos las especies de mamíferos documentadas en ambos asentamientos.

Bovinos (Bos taurus Linné, 1758). Contamos con un único resto procedente del llamado fondo 9 de VA-I, representado por un fragmento de diáfisis de metápodo, asignado con dudas a esta especie. Un registro absoluto tan reducido, obviamente impide realizar valoraciones en relación al papel que dicho animal pudiera aportar a la economía de la población asentada en esta área. Tan sólo quedaría apuntar que en total, los restos de macromamíferos hallados en estas cinco estructuras de VA-I ascenderían tan sólo a ocho, los cuales representan un $4,14 \%$ del total osteológico recuperado (presentado en NR) y debido a su tamaño hasta un $20 \%$ del PR total. Cómo ya adelantamos, en IAA sólo diez restos han sido incluidos como pertenecientes a macromamíferos, sin poder determinar orden o género.

Cerdo o jabalí (Sus scrofa Linné, 1758). En VA-I esta especie dispone de 25 restos, los cuales pertenecen 
en su mayoría a individuos inmaduros y subadultos. Concretamente, procedente del fondo 9 contamos con varios elementos pertenecientes al cráneo de un individuo juvenil, inferior a un año de edad y al que quizás pudieran pertenecer diversos restos del aparato apendicular, todos sin epifisar. De la misma forma, en el fondo 21 se han hallado diversos elementos apendiculares pertenecientes como mínimo a un individuo infantil, al que bien pudiera pertenecer un fragmento de hemimandíbula derecha con el $\mathrm{Pd}_{4}$ libre de desgaste. El resto de los elementos adscritos a esta especie corresponden a inmaduros y subadultos, contando con algunos restos escasos (fondo 22A) que corresponderían a un individuo adulto o subadulto. En total, y teniendo en cuenta estos datos, obtendríamos un mínimo de tres individuos para el conjunto de las cinco estructuras: uno infantil, otro juvenil y al menos un subadulto. La ausencia de ejemplares de gran talla, así como la escasa edad de los tres individuos identificados, nos inclina a situarlos en la variedad doméstica. Por otra parte, las marcas que muestran algunos restos dispersos entre las cinco estructuras podrían hacer referencia a la acción tanto de suidos como de cánidos domésticos sobre el registro, estando este último taxón, ausente en la muestra seleccionada.

Por su parte en IAA, los suidos constituyen el grupo mastozoológico identificado por género con una mayor representación, integrando un total de 41 restos con un peso $283 \mathrm{~g}$, lo que representa más del $20 \%$ del peso del total y hasta el $50,7 \%$ del peso referido a los restos determinados. En total y manejado en términos absolutos, los restos procedentes de todos los conjuntos y estructuras ascienden a un NMI de seis individuos. De ellos, uno corresponde a un inmaduro infantil, dos a individuos subadultos y tres se han incluido en la cohorte de los adultos. Aun constituyendo un número poco representativo de individuos y elementos osteológicos, la proporción significativa de subadultos e infantiles (que a nivel de restos resulta ligeramente dominante), induce a pensar en la presencia mayoritaria de ejemplares dotados de un estatus doméstico, algunos de los cuales podrían haber sido sacrificados antes de alcanzar el óptimo de peso joven.

La dificultad que conlleva diferenciar los suidos salvajes de los domésticos impide calibrar el valor que la representación de elementos anatómicos pertenecientes al taxón salvaje pueda tener en el registro. El hallazgo de algunos elementos de cierta robustez (una primera falange trasera en la estructura $X$, quizás perteneciente a un macho), podría señalar la presencia del taxón salvaje en la muestra. Dado el estado general de los restos no ha sido posible obtener datos relativos a la proporción de sexos en el registro, no habiéndose hallado ejemplos de caninos o navajas superiores o inferiores pertenecientes uno u otro sexo.

Caprinos (Capra hircus Linné, 1758; Capra cf. pirenaica Linné, 1758; Ovis aries Linné, 1758). Los caprinos aparecen muy poco representados en VA-I, apenas cuatro restos, lo que supone un $10 \%$ y un $2 \%$ respectivamente de la muestra de mamíferos determinados por especie y en total respectivamente. Sumados junto a los de cerdo y al grueso de los mesomamíferos, constituirían en total 118 restos, un $61,13 \%$ del total de la muestra ósea, que traducida en términos del total de PR los elevaría al 71,7\% del peso absoluto del conjunto mastozoológico. Ello da idea de la potencial infrarrepresentación de estos taxones (suidos y caprinos) en el grueso del registro, pudiendo indicar previsiblemente valores superiores a lo inicialmente observado.

Esta muestra tan exigua procedente de VA-I, que apunta a un NMI total de un solo individuo y que comprende tan sólo piezas dentales y algunos fragmentos de diáfisis, nos ha impedido llevar a cabo la diferenciación entre Capra y Ovis, no habiéndose podido obtener en este caso medidas osteométricas dado el deficiente estado debido al elevado grado de fragmentación que presentaba este conjunto. Debido a estas circunstancias, detalles relativos a edad y sexo quedan excluidos de cualquier intento de valoración.

Por el contrario, el grupo de los caprinos constituye en IAA el conjunto de restos más numeroso tras el de los suidos. Entre aquellos identificados por subfamilia y a nivel de género y especie, contamos con un conjunto formado por 38 fragmentos, el 42,5\% del peso de los restos determinados y el $17 \%$ del peso total de conjunto macrofaunístico de mamíferos. En este sentido, 31 restos han sido atribuidos a la subfamilia de los caprinos (Capra/Ovis). Tomado en conjunto y excluyendo los fragmentos que sí han podido determinarse a nivel de especie, dicho grupo ha arrojado un número mínimo de tres individuos. En todo el conjunto de caprinos, la mayor parte de los restos pertenecen a individuos adultos, si bien al menos uno de ellos ha sido atribuido a un ejemplar juvenil-subadulto (entre seis y ocho meses de edad siguiendo la erupción y desgaste dental), al que se le suma un fragmento de coxal izquierdo.

La presencia de oveja (Ovis aries) queda confirmada por el hallazgo de cinco fragmentos con un peso de $94 \mathrm{~g}$, los cuales representan el 16\% del peso de los restos determinados. En este sentido se han podido identificar un mínimo de dos individuos, todos adultos, 
entre los que ha sido posible reconocer un macho y, muy posiblemente, una hembra, gracias a la individualización en la estructura X y XII de dos fragmentos de apófisis córnea o gavilla. En el primero de los casos, la pieza pertenece visiblemente a un carnero, pudiéndose reconocer posibles evidencias del truncado distal de las defensas o desmochado, circunstancia que también se ha citado en otros restos de similar cronología en ámbitos geográficos y cronológicos muy próximos, como en Polideportivo de Martos (Lizcano 1999: 206). Asimismo contamos con un fragmento de apófisis córnea izquierda que, dadas sus características morfológicas, posiblemente perteneció a una oveja, lo que podría apuntar a la existencia de hembras cornadas como ha podido observarse también en otros conjuntos publicados de la región (Hain 1982: 44). En la misma línea, sorprende la presencia de elementos óseos de ciertas proporciones, lo cual parece apoyar la tesis de la existencia en estos momentos en el Sur de Iberia de morfotipos ovinos de grandes dimensiones (hasta los 0,75 m de altura a la cruz) y gran robustez (Lizcano 1999: 206, Morales 1986: 348).

En relación a Capra, contamos con apenas dos elementos óseos asignados a este género en IAA; un fragmento de metápodo distal indeterminado adscrito a Capra hircus en la estructura VIII, y una primera falange delantera derecha, atribuida con dudas a Capra cf. pyrenaica. La presencia de otros restos de caprinos de grandes proporciones (un fragmento de radioulna fusionado de la estructura $\mathrm{X}$ así como un fragmento proximal de metacarpo izquierdo de la estructura VIII), apuntan a ejemplares de ciertas dimensiones, si bien en estos casos particulares se ha optado por no extraerlos del conjunto general de los caprinos indeterminados. En total, entre el resto atribuido a Capra hircus y la primera falange atribuida a Capra cf. pyrenaica, se obtiene un peso de 2 y 5 g respectivamente que, sumados, corresponderían al 1,2\% del peso de los restos determinados. El alto número de restos de mesomamíferos no identificados (398), así como de caprinos determinados tan sólo a nivel de subfamilia, obliga a evitar trazar conclusiones respecto a la proporción real de ovejas y cabras domésticas en la muestra.

Ciervo (Cervus elaphus Linné, 1758). Disponemos de un único fragmento proximal de metatarso izquierdo procedente de la estructura XII de IAA. Si bien su conservación ha imposibilitado la toma de medidas, sus grandes proporciones permiten considerar su probable pertenencia a un individuo de sexo masculino. Su peso, en torno a $6 \mathrm{~g}$, apenas supone el $1 \%$ del peso total de los restos determinados en este yacimiento, siendo por tanto irrelevante su contribución a la biomasa calculada para el conjunto de la macrofauna.

Perro (Canis familiaris Linné, 1758). Sólo en IAA contamos con restos pertenecientes a esta especie, limitados a un único individuo adulto. Una hemimandíbula desdentada, procedente de la estructura $\mathrm{X}$, y un fragmento de III metacarpo izquierdo de la estructura XII, contienen rasgos métricos acordes con los esperados para cánidos domésticos. Por otra parte, sobre el material de las estructuras I, IV, VIII y X, se han documentado trazas de carroñeo, pudiendo constituir una prueba más de su presencia frecuente en el entorno del yacimiento, si bien y como ya hemos indicado resulta problemático discriminar dichas marcas de las producidas por otros animales, caso de los suidos.

Zorro (Vulpes vulpes Linné, 1758). Un canino superior derecho perteneciente a un individuo adulto, representa el único resto adscrito al orden de los carnívoros en VA-I, en este caso un zorro, el cual procede del fondo 9. Su presencia en el yacimiento debe ser considerada como de carácter anecdótico, sin descartar una intrusión debida a factores postdeposicionales (madrigueras o zorreras).

Lepóridos (Oryctolagus cuniculus Linné, 1758; Lepus granatensis Rosenhauer, 1856). En IAA, este grupo se compone de 17 restos en total, correspondientes a un peso de 4,75 g, lo que supone apenas el $0,8 \%$ del peso de los restos determinados (PRD) y apenas el 1\% del peso total de los restos determinados, no excluyendo la posibilidad de que un porcentaje impreciso de estos restos se deba factores de orden postdeposicional o no necesariamente ligados al consumo, como así ha sido puesto de manifiesto en ocasiones (García 2005: 28). De la misma forma, 10 de los 17 restos fueron hallados en la estructura XII, la cual fue sometida a un concienzudo tamizado y flotación de sus sedimentos, presuponiendo un importante sesgo en aquellos contextos no sometidos a este sistema de recuperación del registro. Ello afecta particularmente al grupo de los lagomorfos, cuyos elementos anatómicos suelen describirse indistintamente entre el conjunto de los macrovertebrados (macrofauna) y el de los microvertebrados (microfauna).

De estos 17 restos de lepóridos, seis pertenecen a conejo (Oryctolagus cuniculus), siendo todos ellos adscribibles a un sólo individuo. Por el contrario, la liebre (Lepus granatensis) ha proporcionado tan sólo un húmero procedente de la estructura VIII, no pudiendo ser medido debido a su estado de conservación. En cuanto al resto de los elementos anatómicos documentados, muy fragmentarios y recogidos fundamentalmente en criba, optamos por no atribuirlos a una u otra especie. 
Tabla 1. Verduga Alta I. Número de restos determinados (NRD), peso de los restos determinados (PRD), número mínimo de individuos (NMI) y número de restos (NR).

\begin{tabular}{|l|r|r|r|r|r|r|c|}
\hline \multicolumn{1}{|c|}{ Mammalia } & NRD & NRD \% & \multicolumn{1}{c|}{ PRD } & \multicolumn{1}{c|}{ PRD \% } & NMI & Microvertebrados & NR \\
\hline Sus scrofa (dom./ferus) & 25 & 62,5 & 137,50 & 88,85 & 3 & - & - \\
\hline Caprinae & 4 & 10,0 & 6,00 & 3,87 & 1 & Aves & 2 \\
\hline Bos taurus & 1 & 2,5 & 5,00 & 3,23 & 1 & Lacertidae & 6 \\
\hline Vulpes vulpes & 1 & 2,5 & 0,75 & 0,00 & 1 & Bufonidae & - \\
\hline Oryctolagus cuniculus & 7 & 17,5 & 4,00 & 2,58 & 2 & - & - \\
\hline Lepus granatensis & 2 & 5,0 & 1,50 & 0,01 & 1 & - & $\mathbf{9}$ \\
\hline \multicolumn{1}{|c|}{ Total óseo } & $\mathbf{4 0}$ & - & $\mathbf{1 5 4 , 7} \mathbf{g}$ & - & - & Total & - \\
\hline Unionoida & 7 & - & - & - & - & - & - \\
\hline
\end{tabular}

Tabla 2. Iglesia Antigua de Alcolea. Número de restos determinados (NRD), peso de los restos determinados (PRD), número mínimo de individuos (NMI) y número de restos (NR).

\begin{tabular}{|c|c|c|c|c|c|c|c|}
\hline Mammalia & NRD & NRD \% & PRD & PRD \% & NMI & Microvertebrados & NR \\
\hline Sus scrofa (dom./ferus) & 41 & 41,41 & 283,00 & 50,73 & 6 & Apodemus sylvatic. & 5 \\
\hline Caprinae & 31 & 31,31 & 136,00 & 24,38 & 3 & Microtinae indet. & 5 \\
\hline Ovis aries & 5 & 5,05 & 94,00 & 16,85 & 2 & Rodentia indet. & 16 \\
\hline Capra cf. hircus & 1 & 1,01 & 2,00 & 0,35 & 1 & Soricidae indet & 1 \\
\hline Capra cf. pyrenaica & 1 & 1,01 & 5,00 & 0,89 & 1 & Crocidura russula & 1 \\
\hline Cervus elaphus & 1 & 1,01 & 6,00 & 1,07 & 1 & Aves & 1 \\
\hline Canis familiaris & 2 & 2,02 & 27,00 & 4,84 & 1 & Aves (cáscaras) & 3 \\
\hline Oryctolagus cuniculus & 6 & 6,06 & 3,00 & 0,53 & 1 & Lacertidae & 3 \\
\hline Lepus granatensis & 1 & 1,01 & 0,50 & 0,08 & 1 & Pisces & 3 \\
\hline Leporinae indet. & 10 & 10,10 & 1,25 & 0,22 & - & - & - \\
\hline Total óseo & 99 & - & $557,7 \mathrm{~g}$ & - & - & Total & 38 \\
\hline Unionoida & 55 & - & - & - & - & - & - \\
\hline
\end{tabular}

Respecto al enclave de VA-I, los restos atribuidos a conejo ascienden a un total de siete, lo que supone el $17,5 \%$ del total de mamíferos identificados por especie en los contextos revisados en este asentamiento, siendo su PR reducido a niveles porcentuales. Por su parte, un fragmento de húmero mesodistal izquierdo así como otro de escápula izquierda, pertenecientes a los fondos $22 \mathrm{~A}$ y 21 respectivamente, han sido atribuidos sin reservas a liebre.

Asimismo hemos analizado los marcadores de actividad humana sobre el conjunto de restos óseos de mamíferos. En este sentido, ya hemos hecho referencia al grado de afección térmica presente en el conjunto total de IAA y cuyo máximo exponente se encuentra en la estructura VIII, de la cual procede la mayor parte (317 restos, con un peso de $582 \mathrm{~g}$ ) de los elementos osteológicos visiblemente termoalterados. Casi la totalidad de los estigmas de aprovechamiento en este asentamiento responden a fracturas en fresco, observables generalmente sobre diáfisis de medianos y grandes artiodáctilos. Las marcas de corte con instrumental lítico no resultan 
Tablas 3 y 4. Verduga Alta I e Iglesia Antigua de Alcolea. Número mínimo de partes del esqueleto por especie (NMPS). Ss: Sus scrofa, Bt: Bos taurus, C/O: Capra/Ovis, Vv: Vulpes vulpes, Oc: Oryctolagus cuniculus, Lg: Lepus granatensis, Ce: Cervus elaphus, Oa: Ovis aries, Ch: Capra hircus, O/L: Oryctolagus/Lepus, Cl/f: Canis sp.

\begin{tabular}{|l|c|c|c|c|c|c|}
\hline VA- I NMPS & Ss & $\mathbf{B t}$ & $\mathbf{C / O}$ & $\mathbf{V v}$ & $\mathbf{O c}$ & $\mathbf{L g}$ \\
\hline Maxilar & 1 & - & - & - & - & - \\
\hline Región frnt. & 1 & - & - & - & - & - \\
\hline R. Cigom. & 1 & - & - & - & - & - \\
\hline Dientes sup. & - & - & 2 & 1 & - & - \\
\hline Mandíbula & 4 & - & - & - & - & - \\
\hline Dientes inf. & 3 & - & - & - & - & - \\
\hline Escápula & 1 & - & - & - & - & 1 \\
\hline Húmero & 3 & - & 1 & - & 1 & 1 \\
\hline Ulna & 1 & - & - & - & - & - \\
\hline Radio & 3 & - & - & - & - & - \\
\hline Pelvis & - & - & - & - & 1 & - \\
\hline Fémur & 1 & - & - & - & - & - \\
\hline Tibia & 3 & - & - & - & 2 & - \\
\hline Metatarso & - & - & - & - & 1 & - \\
\hline Metápodo & - & 1 & 1 & - & 1 & - \\
\hline \multicolumn{1}{|c|}{ Total } & $\mathbf{2 2}$ & $\mathbf{1}$ & $\mathbf{4}$ & $\mathbf{1}$ & $\mathbf{6}$ & $\mathbf{2}$ \\
\hline
\end{tabular}

\begin{tabular}{|l|c|c|c|c|c|c|c|c|c|c|}
\hline IAA NMPS & Ss & $\mathbf{C e}$ & $\mathbf{O a}$ & $\mathbf{C h}$ & $\mathbf{C p}$ & $\mathbf{O} / \mathbf{C}$ & $\mathbf{O c}$ & $\mathbf{L g}$ & $\mathbf{O} / \mathbf{L}$ & $\mathbf{C l} / \mathbf{f}$ \\
\hline Gavilla & - & - & 2 & - & - & 1 & - & - & - & - \\
\hline R. Cigom. & 1 & - & - & - & - & - & - & - & - & - \\
\hline Dientes sup. & 2 & - & - & - & - & 2 & - & - & 1 & - \\
\hline Mandíbula & 2 & - & - & - & - & 6 & 2 & - & - & 1 \\
\hline Dientes inf. & 2 & - & - & - & - & 2 & - & - & 1 & - \\
\hline Escápula & 9 & - & - & - & - & 1 & 1 & - & - & - \\
\hline Húmero & 5 & - & 1 & - & - & - & 1 & 1 & - & - \\
\hline Ulna & 1 & - & - & - & - & - & - & - & - & - \\
\hline Radio & 6 & - & 2 & - & - & 1 & - & - & - & - \\
\hline Metacarpo & 4 & - & - & - & - & 3 & - & - & - & 1 \\
\hline Pelvis & 1 & - & - & - & - & 2 & - & - & - & - \\
\hline Tibia & - & - & - & - & - & 2 & 1 & - & - & - \\
\hline Calcáneo & - & - & - & - & - & 1 & - & - & - & - \\
\hline Metatarso & 2 & 1 & - & - & - & - & - & - & - & - \\
\hline Falange $1^{\mathrm{a}}$ & 2 & - & - & - & 1 & 4 & - & - & 2 & - \\
\hline Falange $2^{\mathrm{a}}$ & - & - & - & - & - & - & - & - & 2 & - \\
\hline Falange $3^{\mathrm{a}}$ & 1 & - & - & - & - & - & - & - & - & - \\
\hline Metápodo & 1 & - & - & 1 & - & 1 & - & - & 1 & - \\
\hline \multicolumn{1}{|c|}{ Total } & $\mathbf{3 9}$ & $\mathbf{1}$ & $\mathbf{5}$ & $\mathbf{1}$ & $\mathbf{1}$ & $\mathbf{2 6}$ & $\mathbf{5}$ & $\mathbf{1}$ & $\mathbf{7}$ & $\mathbf{2}$ \\
\hline
\end{tabular}

abundantes, si bien contamos con algunos ejemplos en áreas articulares. Otras marcas, acordes con el fileteado o extracción de la carne, resultan observables a modo de series de cortes oblicuos sobre la superficie externa (lateral) de un segmento de costilla de mesomamífero. A este respecto, el reducido conjunto analizado procedente de VA-I no muestra alteraciones o marcas concluyentes.

Moluscos y peces. La constatación habitual en asentamientos de la vega del Guadalquivir de restos malacológicos compuestos por conchas de bivalvos dulceacuícolas, posee interés adicional al sugerir la explotación cuanto menos episódica de dicha fuente de proteínas. Los bivalvos dulceacuícolas aparececen fragmentados y ascienden en VA-I a siete restos, identificables en su mayor parte al género Unio sp., aunque, a falta de un estudio taxconómico más profundo,

no puede descartarse la presencia en la muestra de otros géneros (Margaritifera, Anodonta y sobre todo Potomida), al presentar un grado de fragmentación sobre el que no nos permitimos avanzar mayores conclusiones. En IAA se han llegado a contabilizar hasta 55 restos fragmentarios de estos moluscos, los cuales se han repartido en un número mínimo de valvas de 14, las cuales integrarían virtualmente siete ejemplares. Dichos restos se reparten entre las estructuras VIII, X, XI y XII, frecuencia que podría dar cuenta de una posible explotación de carácter alimentario. Por otra parte se ha documentado en la estructura XII tres restos (elementos vertebrales) pertenecientes a peces, ejemplares en principio de reducidas dimensiones y que deben atribuirse genéricamente, en ausencia de una clasificación específica, a especies de agua dulce. 


\section{GANADERÍA Y ESTUDIOS ARQUEOZOOLÓGICOS EN LA DEPRESIÓN DEL GUADALQUIVIR ENTRE EL IV Y III MILENIO A.N.E.}

Si bien los análisis de conjuntos arqueozoológicos reducidos y dispersos tienden a beneficiar la generalización de situaciones muy concretas y parciales en el espacio y en el tiempo, producto de un registro sometido a múltiples variables de conservación y recuperación, creemos que al menos pueden servir para bosquejar tímidamente hacia dónde pudieron apuntar las distintas estrategias de ganadería y caza-recolección trazadas por los antiguos pobladores de la Depresión del Guadalquivir a partir de su interacción con las realidades ecológicas propias de cada sector territorial. Un rasgo en apariencia común de dichas estrategias se ancla en la explotación fundamental de caprinos, bovinos y suidos en todo el territorio, sobre los cuales trataremos de rastrear la importancia real de cada cabaña en uno u otro sector. Coincidimos en que ésta y otras inferencias deben ser manejadas con cierta precaución al corresponder a datos publicados aún insuficientes y de validez muy desigual, realizados bajo criterios y metodología dispar en función de cada equipo o investigador y en ciertos casos sobre registros parciales recuperados en circunstancias no siempre ideales (Morales y Riquelme 2004: 41). En concreto, nosotros utilizaremos aquí los valores del numero de restos determinados (NRD) y sus porcentajes por especie o subfamilia (incluyendo las especies salvajes) por cada yacimiento. Hemos elegido esta forma al representar sin duda el índice más utilizado por los distintos investigadores que han tratado esta región, habiendo sido considerado como la mejor variable para evidenciar la importancia relativa de las cabañas domésticas (Morales y Cereijo 1992: 101; en contra, Harrison y Moreno 1985: 72).

Repasando los datos publicados relativos a los listados faunísticos por grupos en el Sur de Iberia (Uerpmann 1979: 160-161, Hain 1982, Nocete 1994, Lizcano 1999: 202, Morales y Riquelme 2004: 46, entre otros), observamos de forma reiterada el predominio de la fauna doméstica, y dentro de ella, el trinomio caprinobovino-porcino como conjunto mayoritario. De hecho, si observamos los datos publicados relativos a las frecuencias de composición faunística en los enclaves arqueológicos de la Depresión del Guadalquivir entre el Neolítico y la Edad del Cobre, el primer rasgo que sorprende es sin duda el dominio de la cabaña doméstica frente a las especies salvajes, representando estas últimas una parte reducida (a menudo inferior al diez por ciento) del conjunto mastozoológico presumiblemente consumido. Frente a autores que han apostado por la coexistencia de hasta cuatro estrategias ganaderas diferenciadas a lo largo de la Depresión (Nocete 2001: 72), en nuestro análisis nos centraremos en una explotación dual deducida a través de las diferencias observables entre los enclaves al aire libre de las tierras altas, donde incluiremos estrictamente para este examen parte de las campiñas del Guadalquivir (junto a la loma de Úbeda, alcor de Carmona y Subbético) (fig. 2) y las tierras bajas, área del paleoestuario y vega estricta del Guadalquivir entre el IV y III milenio a.n.e. (fig. 3).

En el alcor de Carmona (Carmona, Sevilla), aunque a partir de datos preliminares, parece rastrearse desde mediados del IV milenio el desarrollo de una ganadería basada en los caprinos como primera cabaña, seguidos de bovinos y suidos, situación que parece se mantendría durante el III milenio a.n.e. con valores similares (Conlin 2006: 1623). Por su parte en la campiña de Córdoba, hasta ahora sólo se conocen los registros de la Fase A de Torreparedones (Baena-Castro del Río, Córdoba) (atribuida por sus excavadores a la Edad del Cobre) (Cunliffe y Fernández 1999: 275). En el reducido conjunto analizado, se ha puesto de manifiesto la sobrerrepresentación de los caprinos domésticos, seguidos muy de lejos por cerdos y bovinos (Hamilton 1999: 400-401). Las campiñas occidentales jiennenses parecen mostrar un patrón de comportamiento parejo (Nocete 1994, 2001: 75-77), en donde en las fases calcolíticas (III milenio a.n.e.) de Cazalilla (Jaén) (Fases I-II) y en el Cortijo de la Torre (Arjona, Jaén), los valores porcentuales de los restos de caprinos se acercan o sobrepasan el $40 \%$, quedando a la zaga los suidos y bovinos (Nocete 1994: 39 y 89). Por último en la loma de Úbeda (Eras del Alcázar de Úbeda, Jaén), en datos globales obtenidos sobre los contextos de la primera mitad del III milenio a.n.e. y sobre un total de 3.258 restos determinados, los caprinos se limitan a algo más del 31\%, quedando los suidos en un 24\% (Lizcano et al. 2009).

La franja territorial representada por el sector subbético muestra una tendencia en apariencia paralela. En el enclave de Gilena (Sevilla) y a partir de 419 restos determinados procedentes de una estructura circular, los caprinos alcanzan el $46 \%$ de los restos determinados, quedando suidos y bovinos en torno al 30\% (Bernáldez 2009: 130-132, Cruz-Auñón et al. 1991: 325). Los conjuntos más representativos en cuanto a número de restos proceden de los sectores subbéticos jiennense y granadino. En el Polideportivo de Martos (Jaén) cuya principal ocupación se extiende a la segunda mitad del IV milenio, los caprinos alcanzan el $73 \%$ de los restos 


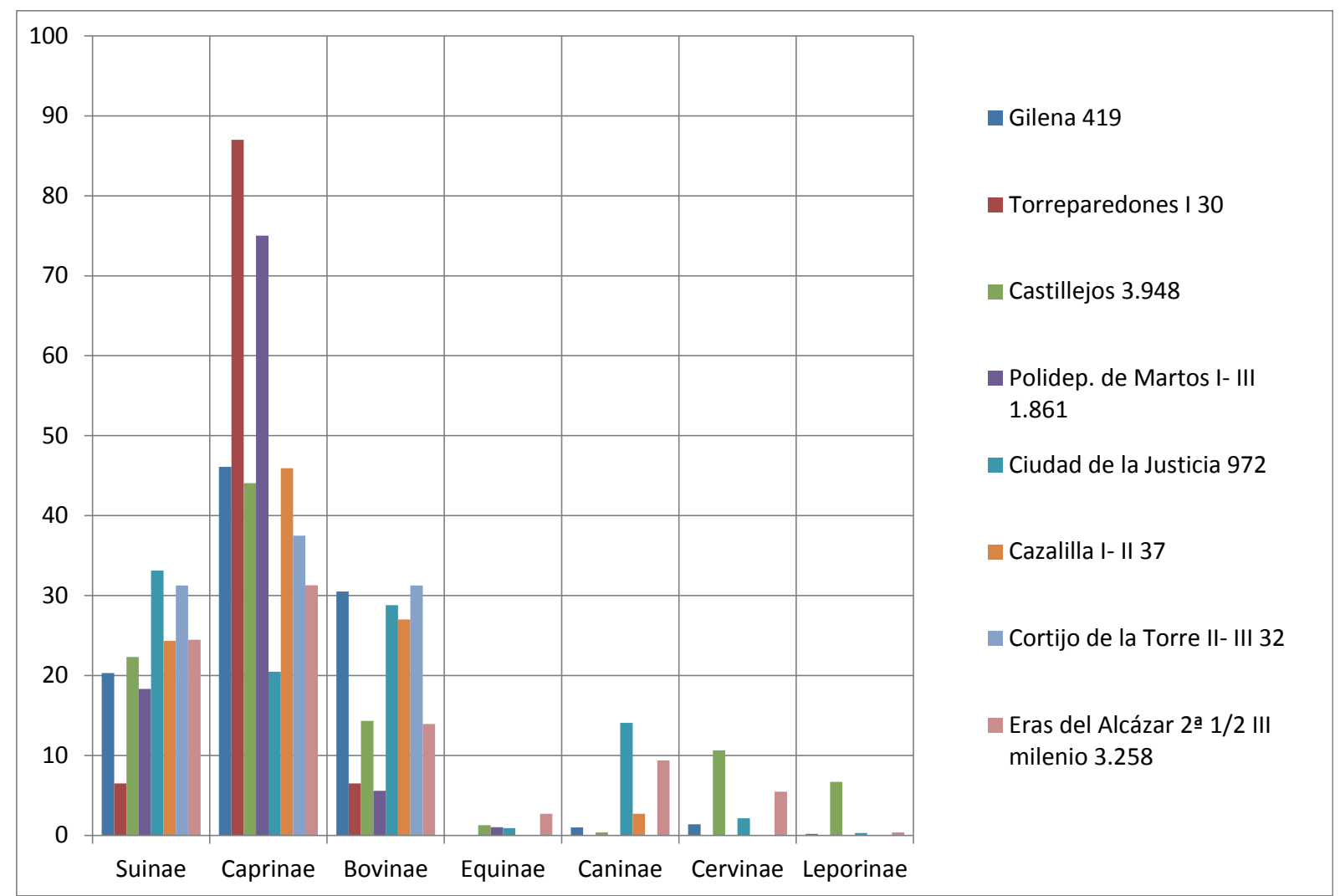

Figura 2. Porcentaje absoluto de NRD por subfamilia en yacimientos de las tierras altas. Valores obtenidos por orden a partir de Bernáldez 2009, Hamilton 1999, Morales y Riquelme 2004, Lizcano et al. 1992 y Cámara et al. 2008, Riquelme 2010, Nocete 1994 y Lizcano et al. 2009.

determinados, quedando los cerdos y los bovinos con el $17 \%$ y el $7 \%$ respectivamente, siempre y cuando excluyamos los animales inhumados en conexión anatómica, evidentemente no consumidos (Cámara et al. 2008: 61). La preponderancia de los caprinos se comprueba también para el Neolítico Final en el poblado de los Castillejos de Montefrío (Granada), en donde los caprinos (incluyendo el taxón salvaje, como en el caso del bovino y el cerdo o jabalí) alcanzan un $44 \%$ del conjunto identificado, seguidos por suidos (el 23\%) y bovinos, con el $14 \%$ del total. El ciervo iría a la zaga como principal taxón salvaje, que junto al corzo alcanza casi el $11 \%$ del total identificado (Morales y Riquelme 2004: 46). Una tendencia muy diferente se observa sin embargo en Marroquíes Bajos (Jaén), en el solar de la Ciudad de la Justicia y correspondiendo a contextos del III milenio a.n.e., donde el cerdo se sitúa en el 33\% de los restos determinados, frente a bovinos y caprinos, con casi el 29\% y 20,5\% cada uno (Riquelme 2010: 119).

Esta última es precisamente la tendencia que parece seguirse en los registros de las tierras bajas, próximas a la vega y entorno estuarino del Guadalquivir y situadas normalmente muy por debajo de los 300 m s.n.m. donde los cerdos aparentan desarrollar cierto protagonismo, lo cual ha sido interpretado como prueba de la existencia de un entorno adehesado ya desde este momento (Nocete 2001: 74). Sin embargo, nosotros consideramos que para la cría del cerdo en áreas ribereñas no resulta estrictamente necesaria la existencia de dicho paisaje, pudiendo conllevar el concurso de otras formas de cría, montanera y engorde.

Valencina de la Concepción (Sevilla), enclave que dominó el estuario del Guadalquivir desde el escalón del Aljarafe durante el III milenio a.n.e., representó el primer conjunto zooarqueológico estudiado sistemáticamente para un poblado calcolítico en el Valle del Guadalquivir. De las estructuras excavadas a mediados de la década de 1970 (Hain 1982), se estudió un conjunto de restos de mamíferos determinados de 28.148, que sigue siendo el mayor conjunto arqueozoológico hasta la fecha publicado en la región. La muestra posee una amplia representación de caprinos, en donde la 


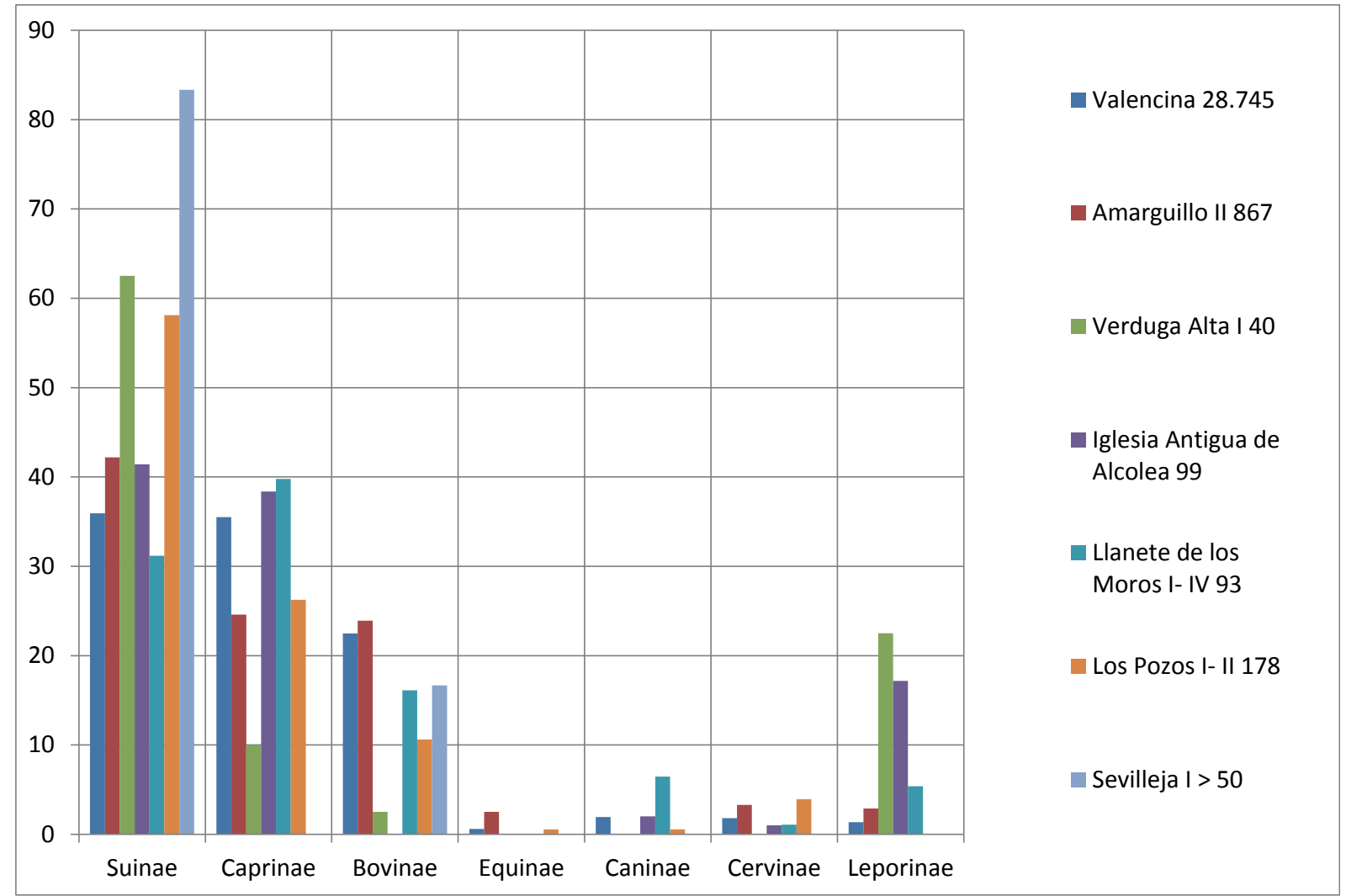

Figura 3. Porcentaje absoluto de NRD por subfamilia en yacimientos de las tierras bajas. Valores obtenidos por orden a partir de Hain 1982 y Abril et al. 2010 (ambos resultados sumados aquí), Bernáldez 2009, Martínez 2011, Liesau 2000, Nocete 1994 y Cámara et al. 2008.

oveja muestra un mayor número de especímenes identificados. Sin embargo, a nivel de restos determinados (NRD), los suidos se muestran sólo ligeramente dominantes, seguidos del bovino. Un trabajo reciente efectuado sobre 597 restos procedentes de 15 estructuras excavadas en el sector IV del "Barrio Metalúrgico", con cronologías centradas en la primera mitad del III milenio a.n.e., ha vuelto a reiterar la importancia del porcino en este enclave seguido de los bovinos y de lejos los caprinos (fundamentalmente ovejas) (Abril et al. 2010: 92).

En el entorno transicional entre la vega del bajo Guadalquivir y el entorno estuarino de su paleodesembocadura, el estudio preliminar realizado sobre el material recuperado en dos estructuras siliformes del Parque de Miraflores (Sevilla), con cuatro dataciones dentro de la primera mitad del III milenio a.n.e., sitúa a cerdos y caprinos como las especies más representadas, seguidas del bovino, el jabalí y el perro (Lara et al. 2004: 249). Para el caso de los 867 restos determinados del poblado del Amarguillo II (Los Molares, Sevilla)
(Cabrero et al. 1997), enclavado en zona de la Campiña muy próxima a terrenos de vega junto a la paleodesembocadura y con una datación de mediados del III milenio, los suidos se mantendrían muy por encima de los caprinos (con más de un 42\%), quedando éstos junto al bovino con valores muy semejantes, en torno al $24 \%$ (Bernáldez 2009: 123).

El estudio arqueozoológico que presentamos en este trabajo, realizado sobre los enclaves de la Verduga Alta y la Iglesia Antigua de Alcolea, viene a sumarse a otros efectuados en el entorno de la vega del medio y alto Guadalquivir; el Llanete de los Moros (Montoro, Córdoba) (Liesau 2000), Los Pozos (Higuera de Arjona, Jaén) y Sevilleja (Espeluy, Jaén) (Nocete 1994). Tanto los conjuntos recuperados en los asentamientos aquí presentados como en los que acabamos de citar, los repertorios osteológicos analizados no resultan ni mucho menos suficientemente representativos en cuanto a número, por lo que las hipótesis surgidas a partir de su cotejo deberán ser consideradas en su justa medida como de carácter preliminar, a la espera de que 
nuevos registros puedan sumarse a estos conjuntos en orden geográfico y cronológico. En estos conjuntos, a excepción del estudiado en Llanete de los Moros donde los caprinos superaban ligeramente a los suidos, tanto en la Fase I de Sevilleja como en los Pozos, el cerdo era la especie predominante, superando ampliamente el 50\% de los restos determinados (Nocete 1994: 77, Cámara et al. 2008) (fig. 3).

\section{EL PAPEL DE LOS RECURSOS FLUVIALES Y ESTUARINOS EN EL GUADALQUIVIR ENTRE EL IV Y III MILENIO A.N.E.}

Sin duda uno de los rasgos geográficos fundamentales de la vega del Guadalquivir lo constituye el propio cauce y sus aguas, las cuales han disfrutado hasta hace poco tiempo de una biodiversidad muy amplia, representada por multitud de especies de vertebrados y moluscos de agua dulce. Dentro de los primeros, los peces han representado un recurso histórico de primer orden para los pobladores de sus riberas. En este sentido, los datos relativos al consumo de peces en asentamientos de la ribera del Guadalquivir en contextos del IV-III milenios a.n.e. resultan en la actualidad muy escasos y fragmentarios, siendo los restos de ictiofauna recuperados en la estructura XII de Iglesia Antigua de Alcolea una de las escasas pruebas del posible aprovechamiento de dicho recurso.

En otros ámbitos del sur de Iberia se ha citado la presencia de restos de peces, si bien ligados a entornos fluviomarinos, sobre los que cabe mencionar los datos procedentes de la Ría de Huelva y del paleoestuario del Guadalquivir, donde se han recogido la mayor parte de los testimonios. Así en la Fase I de Papa Uvas (Aljaraque, Huelva), se tiene documentado el hallazgo de peces óseos como la dorada (Sparus aurata Linné, 1758), así como de diversos fragmentos óseos de mamíferos marinos (cetáceos, probablemente ballenas o cachalotes) (Morales 1985: 256, Morales y Cereijo 1992: 100). Recientemente, en el enclave del Seminario/PP-8 (Huelva) han sido hallados restos de peces en conexión anatómica en el interior de estructuras siliformes, asociados a inhumaciones de perros y cerdos domésticos (Vera y Linares com. pers.). Asímismo, en Valencina de la Concepción, destaca entre otras especies el esturión (Acipenser sturio Linné, 1758) (Hain 1982: 136), extinguido a lo largo del pasado siglo en esta cuenca y su desembocadura.

Sin embargo y probablemente por motivos de orden tafonómico y de conservación diferencial, son los moluscos y dentro de éstos los bivalvos los representantes de la fauna acuática con mayor número de citas publicadas, tanto en entornos puramente fluviomarinos (estuarios del Guadalquivir y del Tinto y el Odiel), como estrictamente fluviales, centrándonos en éste último caso en los asentamientos de la vega estricta del Guadalquivir y los situados a proximidad del curso bajo de sus cauces tributarios. Ambos entornos, fluviomarino y fluvial, parecen contar con un género de bivalvo propio para cada uno de ellos: $\mathrm{Ru}-$ ditapes y Unio.

Ruditapes decussatus Linné, 1758, es un molusco propio de rías, esteros y áreas arenosas de zona intermareal, donde vive enterrado a escasa profundidad (Alex et al. 2004: 330). La explotación de esta especie se rastrea al menos desde el inicio de la economía de producción en el entorno de la Ría de Huelva, conociéndose concheros (Cañada Honda y el Grillito) conformados por los restos de millares de ejemplares (Borja et al. 1994). La presencia de este bivalvo resulta muy abundante en alguna de las estructuras circulares excavadas recientemente en el Seminario/PP8 de Huelva (datadas en la segunda mitad del IV milenio a.n.e.), donde llegan a constituir auténticas acumulaciones (Vera y Linares com. pers.). De la misma forma Ruditapes aparece en todas las fases de Papa Uvas, yacimiento en el que diversas estructuras siliformes depararon decenas de kilos de conchas interpretadas como residuos alimentarios (Luque 1985: 260, Moreno 1992: 33). Dichos restos representan más del $93 \%$ del peso de los moluscos contabilizados en las campañas publicadas, compartiendo espacio (aunque en mucha menor proporción) con restos de otros habitantes de fondos arenoso-fangosos, principalmente navajas (Solen marginatus Pulteney, 1799) (Luque 1985: 259, Morales 1986: 348).

Ruditapes decussatus también se halla presente en los asentamientos próximos al antiguo estuario del Guadalquivir, donde desde el Neolítico Antiguo-Medio se rastrea su explotación en el enclave del Alcázar de Lebrija (Sevilla), junto a Cerastoderma edule Linné, 1758, Solen marginatus y Bolinus brandaris Linné, 1758, entre otras especies (Bernáldez y Bernáldez 2000: 139). En momentos más recientes, Ruditapes decussatus resulta extraordinariamente abundante en el enclave de Valencina de la Concepción, que dominó durante la Edad del Cobre la antigua boca de entrada al Guadalquivir. Así, junto a restos de otras especies obtenidas en mucha menor proporción (sobre todo Pecten maximus Linné, 1758; Solen marginatus y Patella sp.), el estudio del conjunto extraído (Hain 1982: 19) 


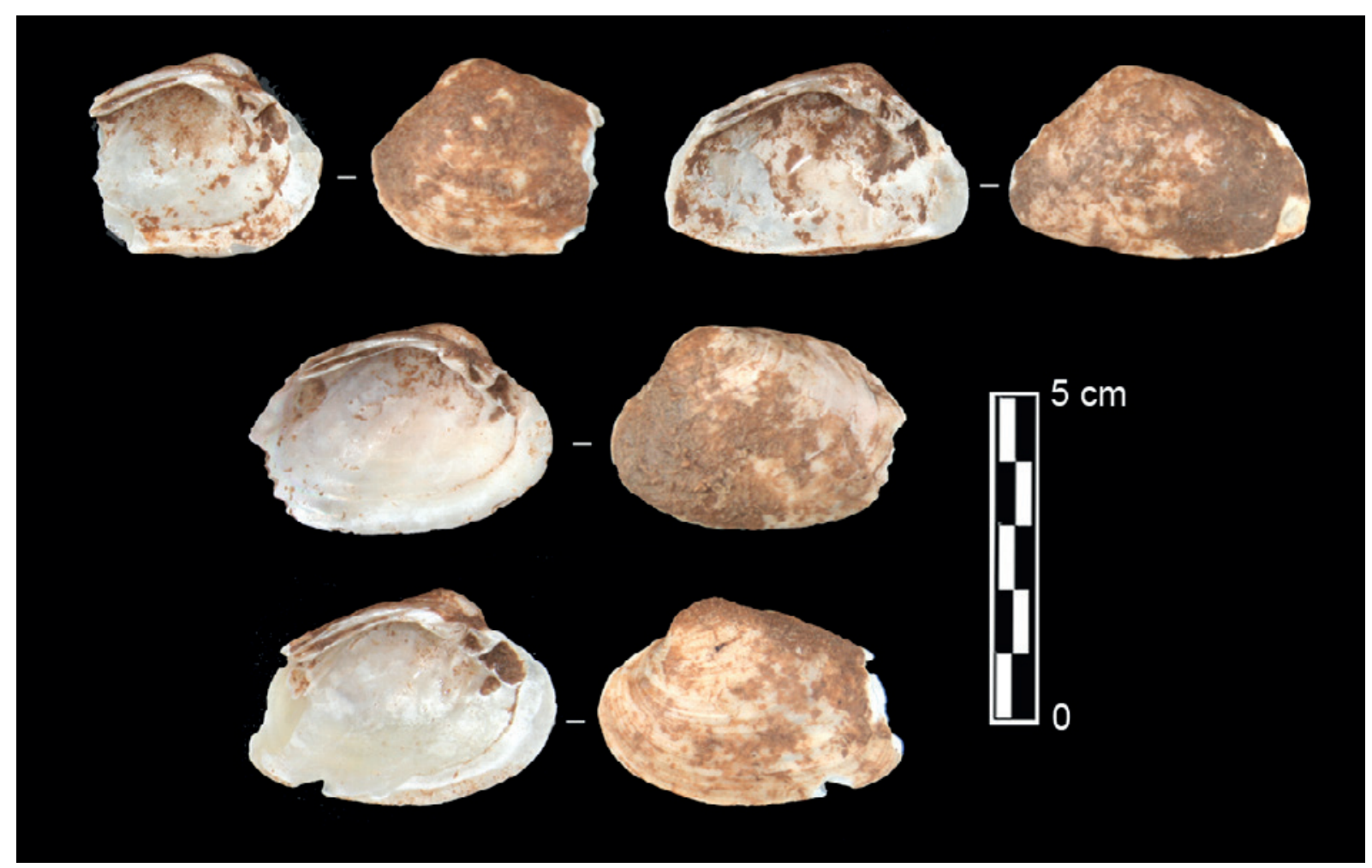

Figura 4. Valvas de Potomida littoralis Cuvier, 1798, procedentes del fondo 10 de Casa del Tabaco (El Carpio, Córdoba).

contabilizó hasta 1.463 restos adscritos a Ruditapes decussatus (citada en el texto como Venerupis decussata Linné, 1758), lo que podría ser indicativo de la explotación de este molusco de forma similar a lo observado en los enclaves de la Ría de Huelva. De la misma forma, en las estructuras siliformes excavadas en el Parque de Miraflores (Sevilla), destacan especialmente en abundancia esta especie, unida de la misma forma a otros bivalvos de fondos fangosos como Tellina sp. (Lara et al. 2004: 249).

Remontando el Guadalquivir y alejándonos de las aguas salobres, la comunidad biológica cambia considerablemente. Así, encontramos especies propias de los fondos limosos-margosos de las aguas continentales como los mejillones de agua dulce o náyades (Unionoida). Estas especies son consideradas en la actualidad un bioindicador fiable de la salud de las aguas de los ríos peninsulares, habiendo descendido su densidad y distribución en el Guadalquivir de forma alarmante en el último siglo (Barea-Azcón et al. 2009: 34).

La dificultad de identificar en términos de especie estos bivalvos, suele llevar aparejada su identificación genérica (Unio sp.), si bien en la actualidad tan sólo se cita en el Guadalquivir una especie de dicho género
(Unio delphinus Spengler, 1793), junto al de Anodonta y Potomida, esta última muy abundante (Barea et al. 2009: 34), existiendo hasta tiempos históricos el género Margaritifera (Araujo y Moreno 1999, Lozano et al. 2004).

Lejos de las concentraciones de valvas de Ruditapes observadas en concheros o en los asentamientos del entorno fluviomarino, la presencia de náyades resulta ,sin embargo, constante en los enclaves ocupados entre el IV y III milenio a.n.e. próximos al Guadalquivir, revelándose su presencia también en Valencina de la Concepción (citada sin confirmación posterior como Unio crassus Philipson, 1788) (Hain 1982: 19), Carmona (Cruz-Auñón y Jiménez 1985: 428, Conlin 2004: 376), la Morita (Cantillana) (Acosta et al. 1987: 151), Ermita de San Pedro (El Carpio) (Martínez 2007: 11), Llanete de los Moros (Montoro) (Liesau 2000: 129), amén de los restos citados en este trabajo procedentes de la Verduga Alta (Palma del Río), Iglesia Antigua de Alcolea (Córdoba) y Casa del Tabaco (el Carpio, Córdoba) (Martínez en prensa), tanto en estructuras con ergología propia del III milenio a.n.e., donde son muy abundantes, como en la estructura 10 (Neolítico TardíoFinal), de donde proceden al menos seis valvas (fig. 4). 


\section{DISCUSIÓN}

Desconocemos hasta qué punto la aparente preferencia por caprinos domésticos o suidos constituye un indicador fiable de hábitos económicos diferenciados entre las tierras altas y la llanura aluvial del Guadalquivir entre la segunda mitad del IV milenio a.n.e. y la mayor parte del milenio siguiente. En todo caso debemos preguntarnos por el origen de las diferencias observadas entre ambos sectores y el supuesto mayor peso de la ganadería porcina en las tierras bajas. Es posible que la cría del cerdo contara con un papel destacado en los entornos ribereños de la vega, beneficiándose de las orillas húmedas de las márgenes del río y de la existencia de una biodiversidad vegetal y animal muy alta. Ello podría verse complementado por la presencia de abundante agua y una ripisilva de gran productividad. Por su parte, en estos ambientes el pastoreo de caprinos a media y larga distancia cumpliría un papel secundario al ser éstos menos exigentes ecológicamente, manteniendo en cambio un buen rendimiento en tierras de matorral y escasa cubierta arbórea aprovechable (Harrison y Moreno 1985: 75).

Sin embargo, frente a la idea anterior, creemos que las diferencias en los regímenes agrícolas previsiblemente desarrollados en cada uno de estos ambientes, podrían constituir un factor nada desdeñable (o incluso determinante) a la hora de apostar por una u otra cabaña. La antropización creciente observada en las secuencias paleobotánicas del Alto Guadalquivir y Sierra de Segura (Fuentes et al. 2007: 90, Carrión 2010), así como la proliferación de ocupaciones sobre todo a partir de mediados del IV milenio a.n.e. en la vega y campiñas del Guadalquivir, asumen una amplia y generalizada explotación agrícola de estos extensos territorios a partir del Neolítico Final, ocupación que ha sido denominada por ciertos autores bajo el término de "Conquista del Secano" (Nocete 1994: 294, Bernabeu 1995: 57) y donde probablemente actuaron nuevas formas de intensificación agraria y ganadera.

Por su parte, desde los inicios de la economía productiva, se ha señalado en el Sur y franja mediterránea ibérica la coexistencia de una cierta variedad de taxones cultivados, tales como distintos tipos de cereales vestidos y desnudos así como leguminosas, estando desde el primer momento representadas el haba (Vicia faba), la lenteja (Lens culinaris) o el guisante (Pisum sativum) (Zapata et al. 2004: 297), defendiéndose una transición relativamente rápida a una agricultura diversificada (Peña y Zapata 2010: 194), adaptada por tanto a la existencia de diferentes nichos ecológicos. El mayor protagonismo de los cerdos en las ubicaciones próximas a la vega estricta del Guadalquivir contra el frecuente dominio absoluto de los caprinos en los enclaves de piedemonte y campiña, podría estar no solamente relacionado con las posibilidades de la cría de esta cabaña en ambientes húmedos y medios de mayor productividad natural, dadas las exigencias ecológicas de los suidos respecto a temperatura, sombra y humedad, sino también en términos de eficiencia con el cultivo asignado a cada ambiente y su rendimiento productivo.

Así, podría resultar muy rentable alimentar a los cerdos con residuos agrícolas procedentes de la cosecha de leguminosas (vegetales de bajo contenido en celulosa), vainas o tallos de fabáceas, las cuales rinden bien sobre suelos de vega de cierta humedad, a diferencia de su peor adaptación a los suelos campiñeses. En este sentido, ya se ha señalado para el II milenio a.n.e. en el Sureste, la posibilidad del cultivo de leguminosas (Vicia faba) probablemente a proximidad de cursos de agua (Castro et al. 1998: 44). Por el contrario, los residuos fundamentales que constituyen la agricultura cerealista de secano extendida en las tierras altas de la campiña y piedemonte subbético, centrada en los tallos y paja de la mies, serían ciertamente inútiles para la alimentación del cerdo, obligando a los animales a procurarse el alimento en encinares próximos, así como a almacenar bellota en el poblado en caso de no contar con residuos suficientes procedentes fundamentalmente de la alimentación humana para su cría sedentaria. En este sentido, las bellotas facilitan el engorde del animal, si bien es conocida la dificultad de alimentar al cerdo con estos frutos durante todo el año (Badal 2002: 143). Frente a esto, tanto el barbecho agrícola como la paja resultante de la agricultura intensiva cerealista, constituye un excelente alimento suplementario para el ganado rumiante (bovino y caprino fundamentalmente).

Fijando la vista en el otro extremo del Mediterráneo, debemos aludir a los estudios realizados en la región Sirio-Palestina, donde en los establecimientos ocupados en el V y IV milenio (sin calibrar) a.n.e., la presencia de restos de cerdo parece verse determinada por los límites de la agricultura de secano, siendo abundantes en aquellos enclaves situados junto al río Jordán e inexistentes en áreas de escasa pluviometría anual. En esta región se ha destacado una clara correlación entre entornos húmedos y la presencia del cerdo doméstico, disminuyendo éste de forma progresiva a medida que avancen las condiciones de aridez a lo largo del III milenio, sólo subsistiendo en aquellos emplazamientos dotados de una agricultura de irrigación (Grigson 2007: 103). Del mismo modo y ya en el conjunto general de la Depresión del Guadalquivir, 
sin querer negar la crianza y gestión de caprinos y cerdos en ambientes distintos a los descritos, podemos apuntar la presencia más destacada del cerdo en las tierras bajas en términos de eficiencia y rendimiento.

Por su parte, el interés que guarda el bovino en sintonía por lo propuesto por otros autores (Sherratt 2006), viene dado, más que por su aporte cárnico en términos de biomasa, por su previsible papel como fuerza de tracción a partir de mediados del IV milenio a.n.e., indispensable en la "Conquista del Secano" ejercida en las campiñas del Guadalquivir. Ello indudablemente debe tener correspondencia en el registro arqueológico en forma de patologías óseas debido a sobreesfuerzo, pruebas de la práctica de la castración o del retraso evidente de las edades de sacrificio, evidencias que de momento y a excepción del estudio realizado en Valencina de la Concepción (Hain 1982: 26) resultan esquivas (Cámara et al. 2010: 302). Las hembras podrían llegar a compartir con ovejas y cabras su papel como proveedor de lácteos, habiéndose destacado para estas últimas una previsible movilidad estacional en tierras del piedemonte subbético (Cámara et al. 2008: 61, Lizcano et al. 2004: 236). En cuanto a la oveja, sin embargo, y pese a que se ha aludido a su papel como productor de lana (Lizcano et al. 1992: 87, Cámara et al. 2008: 78), debemos resaltar la probable ausencia de razas laneras en Europa Occidental antes del III milenio a.n.e. (Sherrat 1981: 282, 2006: 338, Davis 1989: 164), encontrándose el primer testimonio de este tejido en el sur de Iberia asociado a la llamada "Momia de Galera" (19001600 a.n.e.) (Molina et al. 2003: 121).

Respecto a la posibilidad de que la recolección de bivalvos dulceacuícuolas en entornos fluviales represente un reflejo de las actividades de subsistencia llevadas a cabo en enclaves de estuario con la recolección de Ruditapes, no es algo desde luego fácil de determinar, desconociendo la existencia de concheros o acumulaciones grandes de valvas de náyades en la franja próxima a la llanura aluvial de la vega del Guadalquivir, algo difícil dada su débil concentración en el ecosistema y su mayor fragilidad ecológica si la comparamos con ambientes costeros. En algunos casos, su presencia puede estar relacionada ciertamente con usos tecnológicos o artesanales, así como ser de origen multicausal o ajeno a la actividad humana, mientras que sí conocemos pruebas precisas de su consumo directo en la vega del Guadiana desde el Neolítico Antiguo (Gonçalves et al. 2003: 88). En todo caso la extensa representación de náyades en los asentamientos ribereños resulta muy indicativa como posible prueba de la existencia de hábitos recolectores en medio acuático, a semejanza de lo observado en algunos poblados neolíticos del Danubio, donde se ha podido demostrar la explotación intensiva de este recurso (Bălăşescu et al. 2005: 71).

\section{CONCLUSIONES}

Consideramos que ante los datos disponibles, aun siendo de momento escasos, podemos defender la consolidación al menos desde mediados del IV milenio a.n.e., de una economía animal diferenciada en el interior de la Depresión del Guadalquivir, especializada en explotar las ventajas que brindaría cada piso o ambiente ecológico existente en el entorno. En este sistema, los diversos factores ambientales, así como la influencia de las formas de agricultura y tipos de cultivo, tendrían una gran importancia en función de coste y rendimiento. Este fenómeno vendría en paralelo a la fragua de la agricultura extensiva cerealista de secano en las campiñas del sur del Guadalquivir, desarrollándose un verdadero "Policultivo Ganadero" (Harrison y Moreno 1985), interpretable más en términos de eficiencia productiva que de especialización económica. Dicha gestión diferencial de los recursos podría verse plenamente desarrollada en un período coincidente con un estadio avanzado de intensificación agrícola y complejización social, en el que la ocupación de las campiñas y vegas muestran a partir de este momento una densidad sin precedentes históricos, protagonizada por enclaves al aire libre dotados de estructuras siliformes y formas cerámicas de gran amplitud y carena baja.

El aprovechamiento de los recursos fluviales, fundamentado en el marisqueo de bivalvos de agua dulce y previsiblemente en la captura de peces, pudo contar con un papel más destacado de lo visto hasta ahora, en el que las poblaciones prehistóricas simplemente explotaron un recurso disponible y de fácil obtención. Sin embargo, con los datos hasta ahora existentes, resulta difícil por el momento evaluar la importancia cuantitativa que pudo tener en los asentamientos próximos al Guadalquivir, siendo el peso de esta actividad predatoria probablemente menor en el área ribereña en que en los entornos fluviomarinos próximos al Paleoestuario del Guadalquivir y de la Ría de Hueva.

\section{AGRADECIMIENTOS}

Los trabajos en los yacimientos de la Verduga Alta y Antigua Iglesia de Alcolea, autorizados por la Consejería de Cultura de la Junta de Andalucía, fueron 
dirigidos por Rafael Clapés Salmoral, Ricardo García Benavente, M. Reyes Lopera Delgado y Rafael Nieto Medina (DEP) a quienes agracecemos muchos de los datos recogidos en este trabajo. Agradecemos de la misma forma a J. Antonio Cámara Serrano algunos datos cuantitativos pertenecientes a enclaves del Alto Guadalquivir, así como a J. Carlos Vera Rodríguez y J. Antonio Linares Catela la información brindada en lo que respecta al yacimiento del Seminario-La Orden/PP 8 (Huelva). Este trabajo se ha desarrollado dentro del Grupo PAI HUM 262, dirigido por José C. Martín de la Cruz.

\section{BIBLIOGRAFÍA}

Abril, D.; Nocete, F.; Riquelme, J. A.; Bayona, M. e Inacio, N. (2010): “Zooarqueología del III Milenio A.N.E.: El barrio metalúrgico de Valencina de la Concepción (Sevilla)". Complutum 21(1): 87-100.

Acosta, P.; Cabrero, R.; Cruz-Auñón, R. y Hurtado, V. (1987): "Informe Preliminar sobre las excavaciones de La Morita (Cantillana, Sevilla), 1985". Anuario Arqueológico de Andalucía 1985 (II): 150-152.

Alex, E.; Nocete, F.; Nieto, J. M.; Sáez, R. y Bayona, M.R. (2004): "Estudio del impacto ambiental de la metalurgia prehistórica del Andévalo onubense: Contaminación de aguas, deforestación y erosión", en F. Nocete (ed.), Odiel; Proyecto de Investigación Arqueológica para el análisis del Origen de la Desigualdad Social en el Suroeste de la Península, pp. 325-341. Sevilla, Junta de Andalucía.

Araujo, R. y Moreno, R. (1999): "Former Iberian distribution of Margaritifera auricularia (Spengler) (Bivalvia: Margaritiferidae)". Iberus 17(I): 127-136.

Badal, E. (2002): "Bosques, campos y pastos: el potencial económico de la vegetación mediterránea", En E. Badal, J. Bernabeu y B. Martí (eds.), Saguntum Extra-5. El Paisaje en el Neolitico Mediterráneo, pp. 129-146.

Bălăşescu A.; Radu V. y Moise D. (2005): Omul şi mediul animal între mileniile VII-IV i.e.n. la Dunarea de Jos. Bucarest, Biblioteca Muzeului Naţional, Seria Cercetări Pluridisciplinare 11.

Barea Azcón, J.M.; Araujo, R.; Machordom, A.; Coledo, J.; Cardoso, J.; Ballesteros-Duperón, E. y Irurita, J.M. (2009): "Las náyades de la fauna andaluza. Situación actual y conservación”. Quercus 278: 30-36.

Bernabeu, J. (1995): “Origen y consolidación de las sociedades agrícolas en el País valenciano entre el Neolítico y la Edad del Bronce", Actes de les
Jornades d'Arqueología (Alfàs del Pi, 1994), pp. 37-60. Valencia, Consellería de Cultura.

Bernáldez, E. y Bernáldez, M. (2000): “La basura orgánica de Lebrija en otros tiempos. Estudio paleobiológico y taxonómico del yacimiento arqueológico de la Calle Alcazaba de Lebrija (Sevilla)". PH. Boletín del Instituto Andaluz de Patrimonio Histórico 32: 134-150.

Bernáldez, E. (2009): Bioestratinomia de Macromamíferos Terrestres de Doñana. Inferencias ecológicas en los yacimientos arqueológicos del SO de Andalucía. Oxford, BAR International Series 1978.

Borja, F., Barral, M.A. y García, J.M. (1994): “Los concheros arqueológicos de Cañada Honda y el Grillito (Estuario del Odiel, Huelva)", Geomorfología en España: III Reunión Nacional de Geomorfología 3, pp. 327-338. Logroño, Sociedad Española de Geomorfología.

Cabrero, R.; Ruiz, M. T.; Cuadrado, L. B. y Sabaté, I. (1997): "El poblado metalúrgico de Amarguillo II en Los Molares (Sevilla) y su entorno inmediato en la campiña: últimas analíticas realizadas". Anuario Arqueológico de Andalucía 1993 II: 131-141.

Cámara, J. A.; Lizcano, R.; Pérez, C. y Gómez, E. (2008): “Apropiación, sacrificio, consumo y exhibición ritual de los animales en el polideportivo de Martos: sus implicaciones en los orígenes de la desigualdad social". Cuadernos de Prehistoria de la Universidad de Granada 18: 55-90.

Cámara, J.A.; Riquelme, J.A.; Pérez, C.; Lizcano, R.; Burgos, A. y Torres, F. (2010): "Sacrificio de animales y ritual en el Polideportivo de Martos-La Alberquilla (Martos, Jaén)". Cuadernos de Prehistoria de la Universidad de Granada 20: 295-327.

Carrión, J.S. (2010): "Expected trends and surprises in the Lateglacial and Holocene vegetation history of the Iberian Peninsula and Balearic Islands". Review of Palaeobotany and Palynology 162: 458-475. http://dx.doi.org/10.1016/j.revpalbo.2009.12.007

Castro, P.; Gili, S.; Lull, V.; Micó, R.; Rihuete, C.; Risch, R. y Sanahuja, M. E. (1998): “Teoría de La producción de la vida social. Mecanismos de explotación en el Sudeste Ibérico". Boletín de Antropología Americana 33: 25-77.

Conlin, E. (2004): "El poblado calcolítico de Carmona (Sevilla)", Actas del II y III Simposio de Prehistoria "Cueva de Nerja”, pp. 370-378. Málaga, Fundación Cueva de Nerja.

Conlin, E. (2006): "Acerca del origen verdadero de Carmona: su secuencia evolutiva en la Edad del Cobre". Carel 4: 1607-1640. 
Cruz-Auñón, R. y Jiménez, J.C. (1985): "Historia crítica del antiguo yacimiento de Campo Real (Carmona)". Habis 16: 417-452.

Cruz-Auñón, R.; Moreno, E. y Rivero, E. (1991): “Experiencias arqueológicas en Gilena (Sevilla)", IInd Deya international conference of prehistory. Recent developments in Western Mediterranean prehistory: archaeological techniques, technology and theory, 1, pp. 313-337. Oxford, BAR International Series 573.

Cunliffe, B. y Fernandez, M. C. (1999): The Guadajoz Project: Andalusia in the First Millennium BC: Torreparedones and Its Hinterland. Oxford, University Press.

Davis, S.J.M. (1989): La arqueología de los animales. Barcelona, Bellaterra.

Fuentes, N.; Carrión, J. S.; Fernández, S.; Nocete, F.; Lizcano, R. y Pérez, C. (2007): “Análisis polínico de los yacimientos arqueológicos Cerro del Alcázar de Baeza y Eras del Alcázar de Úbeda (Jaén)". Anales de Biología 29: 85-93.

Gonçalves, V. S. (2003): "Comer em Regengos no Neolítico. As estruturas de combustão da Área 3 do Xarez 12". Muita Gente poucas antas? Origens, espaços e contextos do megalitismo. Actas do II coloquiointernacional sobre megalitismo, pp. 81-100. Lisboa, Instituto Português de Arqueologia.

García Rivero, D. (2005): "Prehistoria y evolución: Reflexiones sobre la secuencia ecológico-cultural holocénica en el mediodía ibérico". Spal 13: 9-34. http://dx.doi.org/10.12795/spal.2004.i13.01

Grigson, C. (2007): "Culture, ecology, and pigs from the 5 th to the 3 rd millenium $\mathrm{BC}$ around the Fertile Crescent", en U. Albarella, K. Dobney, A. Ervynck y P. Rowley-Conwy (eds.), Pigs and Humans; 10000 Years of Interaction, pp. 83-108. Oxford, University Press.

Hain, F.H. (1982): Kupferzeitliche Tierknochenfunde aus Valencina de la Concepción/Sevilla. Munich, Deutsches Archäologisches Institut.

Hamilton, J. (1999): “The faunal Remains", en B. Cunliffe y M.C. Fernandez (eds.), The Guadajoz Project: Andalusia in the First Millennium BC: Torreparedones and Its Hinterland, pp. 399-401. Oxford, University Press.

Harrison, R.J.; Moreno López, G. (1985): "El policultivo ganadero o la revolución de los productos secundarios". Trabajos de Prehistoria 42: 51-82.

Lara, D.E.; Barragán, D. y Garrido, M. (2004): "El asentamiento calcolítico del parque de Miraflores (Sevilla): resultados preliminares". Spal 13: 245-255. http://dx.doi.org/10.12795/spal.2004.i13.09
Liesau, C. (2000): "Identificación de restos de fauna, Llanete de los Moros (Montoro, Córdoba)", en J. C. Martín de la Cruz, M.P. Sanz y J. Bermúdez (eds.), La Edad del Cobre en el Llanete de los Moros (Montoro). El origen de los pueblos en la Campiña cordobesa, pp. 128-132. Córdoba, Universidad de Córdoba.

Lizcano, R. (1999): El Polideportivo de Martos (Jaén): Un yacimiento Neolítico del IV milenio a. C. Córdoba, Obra social y Cultural Cajasur.

Lizcano, R.; Cámara, J.A.; Riquelme, J.A.; Cabañate, M.L.; Sánchez, A. y Afonso, J.A. (1992): “El Polideportivo de Martos. Producción Económica y Símbolos de Cohesión en un asentamiento del Neolítico final en las Campiñas del Alto Guadalquivir." Cuadernos de Prehistoria de la Universidad de Granada 16-17: 5-101.

Lizcano, R.; Cámara, J.A.; Contreras, F.; Pérez, C. y Burgos, A. (2004): "Continuidad y cambio en comunidades calcolíticas del Alto Guadalquivir", Actas del II y III Simposio de Prehistoria "Cueva de Nerja”, pp. 159-175. Málaga, Fundación Cueva de Nerja.

Lizcano, R.; Nocete, F. y Peramo, A. (2009): Las Eras. Proyecto de puesta en valor y uso social del patrimonio arqueológico de Úbeda (Jaén) [CD-ROM]. Huelva, Universidad de Huelva.

Lozano, M.C.; García, J.A. y Cortés, M. (2004): "Presencia del bivalvo de agua dulce Margaritifera auricularia (Spengler, 1793) en un yacimiento arqueológico de época Califal de Córdoba (España)". Pliocénica 4: 11-15.

Luque, A.A. (1985): "Estudio malacológico", en J. C. Martín de la Cruz, Papa Uvas I. Aljaraque, Huelva. Campañas de 1976 a 1979, pp. 259-264. Madrid, Ministerio de Cultura.

Martínez, R.M. (2007): "La Ermita de San Pedro, El Carpio, Córdoba. La fase prehistórica a través del corte 1. Actividad Arqueológica Puntual de 2005". Antiquitas 19: 5-16.

Martínez, R.M. (2010): “Análisis arqueozoológico de la fase ibérica y medieval del Cerro de la Cruz. Campañas de 2006-2008". Oikos 2: 141-149.

Martínez, R.M. (2011): El IV milenio ANE en la vega del Guadalquivir Medio; entorno, sociedad y cultura material. Tesis Doctoral, Universidad de Córdoba, Inédita.

Martínez, R.M. (En Prensa): "Intervención arqueológica en la Casa del Tabaco (El Carpio, Córdoba)". Anuario Arqueológico de Andalucía 2009.

Martínez, R.M.; García, R. y Clapés, R. (2010a) "La Iglesia Antigua de Alcolea. Un asentamiento del IV 
milenio ANE en la vega del Guadalquivir medio", en J.A. Pérez y E. Romero (eds.), Actas del IV Encuentro de Arqueología del Suroeste Peninsular, Aracena (Huelva) [CD-ROM], pp. 88-106. Huelva, Universidad de Huelva.

Martínez, R.M.; Martín de la Cruz, J.C.; Bretones, M.D. y Ruiz, M.P. (2010b): "El Neolítico en la Vega del Guadalquivir Medio", en J.F. Gibaja, A. F. Carvalho (eds.), Os últimos caçadores-recolectores $e$ as primeiras comunidades produtoras do sul da Península Ibérica e do Norte de Marrocos, pp. 237 246. Faro, Universidade do Algarve.

Molina, F.; Rodríguez, M.O.; Jiménez, S. y Botella, M. (2003): "La sepultura 121 del yacimiento argárico de El Castellón Alto (Galera, Granada)". Trabajos de Prehistoria 60(1), pp. 153-158. http://dx.doi. org/10.3989/tp.2003.v60.i1.127

Morales, A. (1985): “Análisis faunístico del yacimiento de Papa Uvas. Aljaraque-Huelva”, en J.C. Martín de la Cruz (coord.), Papa Uvas I. Aljaraque. Huelva. Campañas de 1976 a 1979, pp. 233-257. Madrid, Ministerio de Cultura.

Morales, A. (1986): "Informe faunístico del yacimiento. Corte C-4.3. Fondo n ${ }^{\circ}$ 3. Sector C", en J.C. Martín de la Cruz (coord.), Papa Uvas II. Aljaraque. Huelva. Campañas de 1981 a 1983, pp. 347350. Madrid, Ministerio de Cultura.

Morales, A. y Cereijo, M.A. (1992): “Consideraciones faunísticas en la transición Neolítico-Calcolítico: el yacimiento arqueológico de Papa Uvas (Huelva)". Archeofauna 1: 87-104.

Morales, A.; Cereijo, M.A.; Brännstöm, P. y Liesau, C. (1994): "The mammals", en E. Roselló y A. Morales (eds.), Castillo de Doña Blanca, pp. 37-69. Oxford, BAR International Series 593.

Morales, A. y Riquelme, J.A. (2004): “Faunas de mamíferos del Neolítico Andaluz: tendencias diacrónicas fiables", en Actas del II y III Simposio de Prehistoria Cueva de Nerja, pp. 41-51. Málaga, Fundación Cueva de Nerja.

Moreno, R. (1992): “La explotación de moluscos en la transición Neolítico-Calcolítico del yacimiento de Papa Uvas (Aljaraque, Huelva)". Archeofauna 1: 33-44.
Murillo, J.F. (1988): “Aproximación al poblamiento calcolítico en el Valle del Guadalquivir. Sector Villarrubia-Palma del Río". Ariadna 4: 5-25.

Nocete, F. (1994): La formación del Estado en las campiñas del alto Guadalquivir (3000-1500 ane). Granada, Servicio de Publicaciones de la Universidad de Granada.

Nocete, F. (2001): Tercer Milenio antes de nuestra era. Relaciones y contradicciones centro/periferia en el Valle del Guadalquivir. Barcelona, Bellaterra.

Peña Chocarro, L. y Zapata, L. (2010): "Neolithic agriculture in southwestern Mediterranean region", en J. F. Gibaja, A. F. Carvalho (eds.), Os últimos caçadores-recolectores e as primeiras comunidades produtoras do sul da Península Ibérica e do Norte de Marrocos, pp. 191-197. Faro, Universidade do Algarve.

Riquelme, J.A. (2010): “Una aproximación a la utilización por el hombre de las especies animales documentadas en la Ciudad de la Justicia de Jaén", Ciudad de la Justicia. Excavaciones arqueológicas, pp. 118-133. Sevilla, Junta de Andalucía.

Sherratt, A. (1981): "Plough and pastoralism: Aspects of the secondary products revolution", en I. Hodder, G. Isaac y N. Hammond (eds.), Pattern of the Past: Studies in honour of David Clark, pp. 261305. Cambridge, University Press.

Sherratt, A. (2006): "La traction animale et la transformation de 1'Europe Néolithique", en P. Pétrequin, R.M. Arbogast, A.M. Pétrequin, S. Van Willigen y M. Bailly (eds.), Premiers chariots, premiers araires. La diffusion de la traction animale en Europe pendant les $I V^{e}$ et $I I I^{e}$ millénaires avant notre ère, pp. 329-359. París, CNRS.

Uerpmann, H.P. (1979): "Informe sobre los restos faunísticos del Corte No 1", en A. Arribas, F. Molina, El poblado de "los Castillejos" en las Peñas de los Gitanos (Montefrío, Granada). Campaña de excavaciones de 1971. El corte núm. 1, pp. 153-168. Granada, Servicio de Publicaciones de la Universidad de Granada.

Zapata, L.; Peña, L.; Pérez, G. y Stika, H.P. (2004): "Early Neolithic Agriculture in the Iberian Peninsula". Journal of World Prehistory 18(4): 283-325. http://dx.doi.org/10.1007/s10963-004-5621-4 